\title{
Tobacco Control launches into cyberspace
}

With the publication of this issue, Tobacco Control leaps into cyberspace with eTC. Thanks to the grant we have received from the Robert Wood Johnson Foundation, the full text of everything you read in the journal will henceforth be available on our web site $<$ www.tobaccocontrol.com $>$. We plan to allow anyone free access to the site for six months. Access control will apply from January 2000. Thereafter, our subscribers will receive a paper copy of the journal and ongoing full text access via password. Non-subscribers will from then only be able to access the tables of contents and abstracts of papers.

We hope that the open period of access will attract many more researchers and policy advocates to our journal and that our subscription numbers will grow as people come to regard Tobacco Control not only as a "must read", but also as an interactive forum for policy and method debate. Going full text online will be just the beginning of what we are planning to do in cyberspace. Options that are now available on our parent $B M \mathcal{F}$ web site <www.bmj.com> include the following.

- Instant response: a facility to send an e-letter in response to any paper or part of the journal
- Advanced publication: placing a paper on the web site as soon as it is accepted, rather than waiting sometimes months for it to be published

- Web-only publications: a capacity to publish peer-reviewed papers on the web which cannot for reasons of space and cost be published in the paper version

- Extra tables and figures: again, the capacity to publish more of an article on the web than space and cost permits in the paper version

- Links to related articles in the same and previous issues of Tobacco Control and all other BMJ Publishing Group publications on HighWire

- Links to PuBMed

Electronic publication is the future of medical publishing. We are pleased to be part of the BMJ Publishing Group stable of research publications that is now widely recognised as being at the leading edge of this exciting development.

Editor
SIMON CHAPMAN

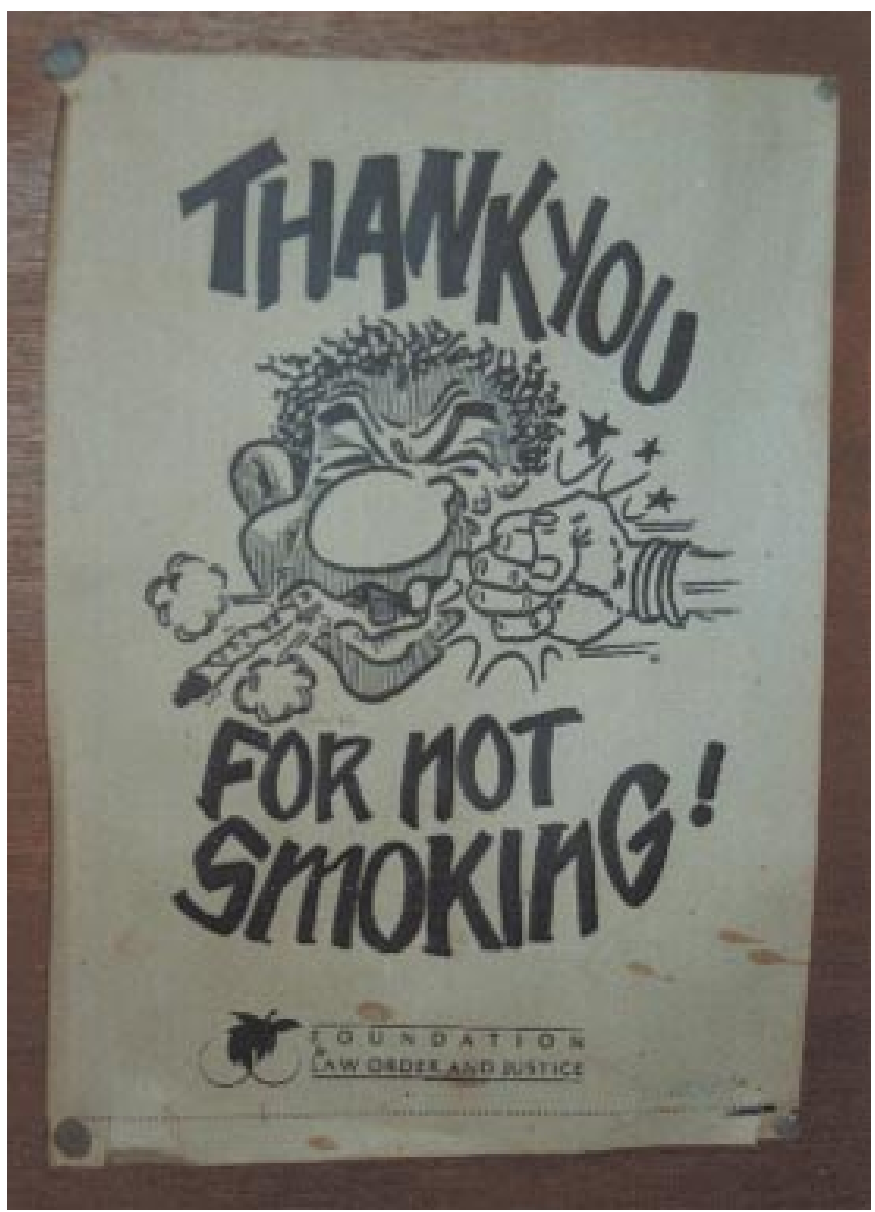

In Papua New Guinea, they don't beat around the bush about passive smoking. Instead the Foundation for Law, Order and Fustice suggests beating around the heads of recalcitrants. This picture was taken by Paul Heaton of New Plymouth, New Zealand in Milne Bay in Papua. Paul reports that there was no-one smoking in the café where he took the photo. 